\title{
Building the Resistance: Eladio Dieste's Digital Work in Cerámica Armada
}

\section{FEDERICO GARCIA LAMMERS}

South Dakota State University
Many archive photographs capture the construction of longspan reinforced masonry, double-curvature shell structures built by the practice of the late Uruguayan engineer Eladio Dieste. There are few photographs of Dieste hovering over models or drawings in his office. In most images, he is speaking with workers while inspecting and standing on formwork - construction materials always within his reach. Images show Dieste working with job captains dedicated to designing the complex choreography of materials and bodies on site. During the second half of the 20th century, his engineering and construction practice, Dieste and Montanez, invented four material innovations in Structural Ceramics or Cerámica Armada. Cerámica Armada combined the abundance of a local material, like clay brick, with the modern advent of steel reinforcement. Dieste's fascination with material was based in the structural resistance to gravity through the combination of material and form.

The virtuality of the digital in "Building the Resistance" is framed by the role of formwork systems designed to build Gaussian Vaults and other the double curvature geometries in Dieste's work. Studying the adjustable and reusable formwork systems designed and constructed by Dieste's practice highlights the implications of making digital work without computational technology or electronic media. Historical knowledge of these systems connects the invention of complex forms with the labor that produced them. Problematizing the representation and construction scope of labor is critical to the ideas of economy proposed by Dieste. In "Architecture and Construction," Dieste suggested that Cosmic Economy was a way to reveal the order of the world by paying close attention to the people behind the construction of buildings (Dieste, 1992).

During a 1990 interview with the architect Mariano Arana, Dieste stated that he rarely made models in his practice, "the model is slower and more expensive than computation - the smaller structures have been the models for the larger ones" (Dieste, 1992). In this passage, he was referring to the slowness of physical models and the speed of numerical calculations as a form of computation. Dieste's work challenged the geometrically planar hegemony of modernism by developing a repertoire of digitally produced forms. The process was digital because bits were used to anticipate and calculate the behavior of atoms - data predicted the behavior of physical matter (Negroponte, 1995). His practice trafficked in data before the ubiquity of computer servers displaced the understanding of physical matter as the product of intimate numerical knowledge. Many engineers, artists, and architects, like Antoni Gaudi, worked through digital means to find forms long before computational tools. Unlike other people investigating the relationship between materiality and virtuality, Dieste did not use any form-finding techniques other than the use of numerical calculations to anticipate material bending and load distribution.

With a sense of Cosmic Economy in mind, how does examining formwork labor become a digital precondition for understanding the material effects of Cerámica Armada? Material lessons from Dieste's work highlight ways to resist gravity as well as the economic and political forces that shape the contemporary relationship between architecture and labor. 


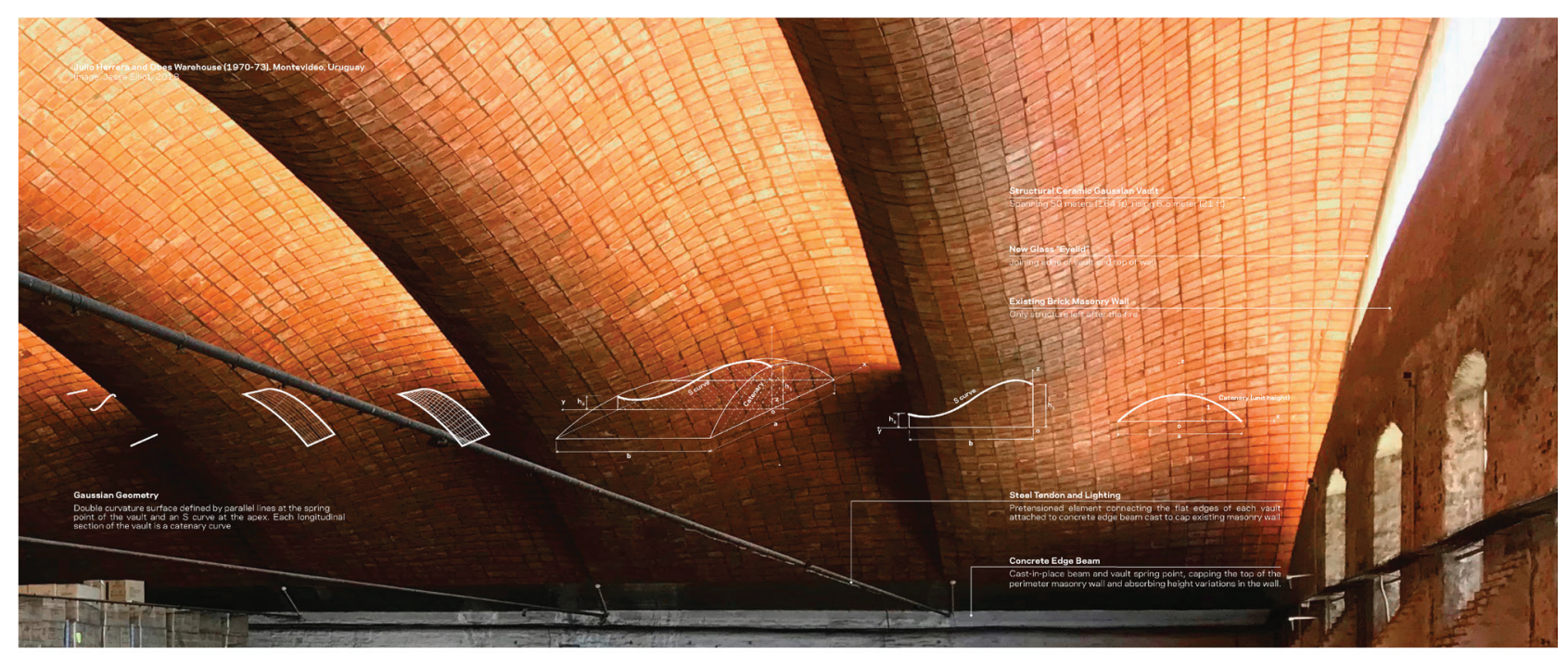

Building the Resistance

Eladio Dieste's Digital Work in Cerámica Armada
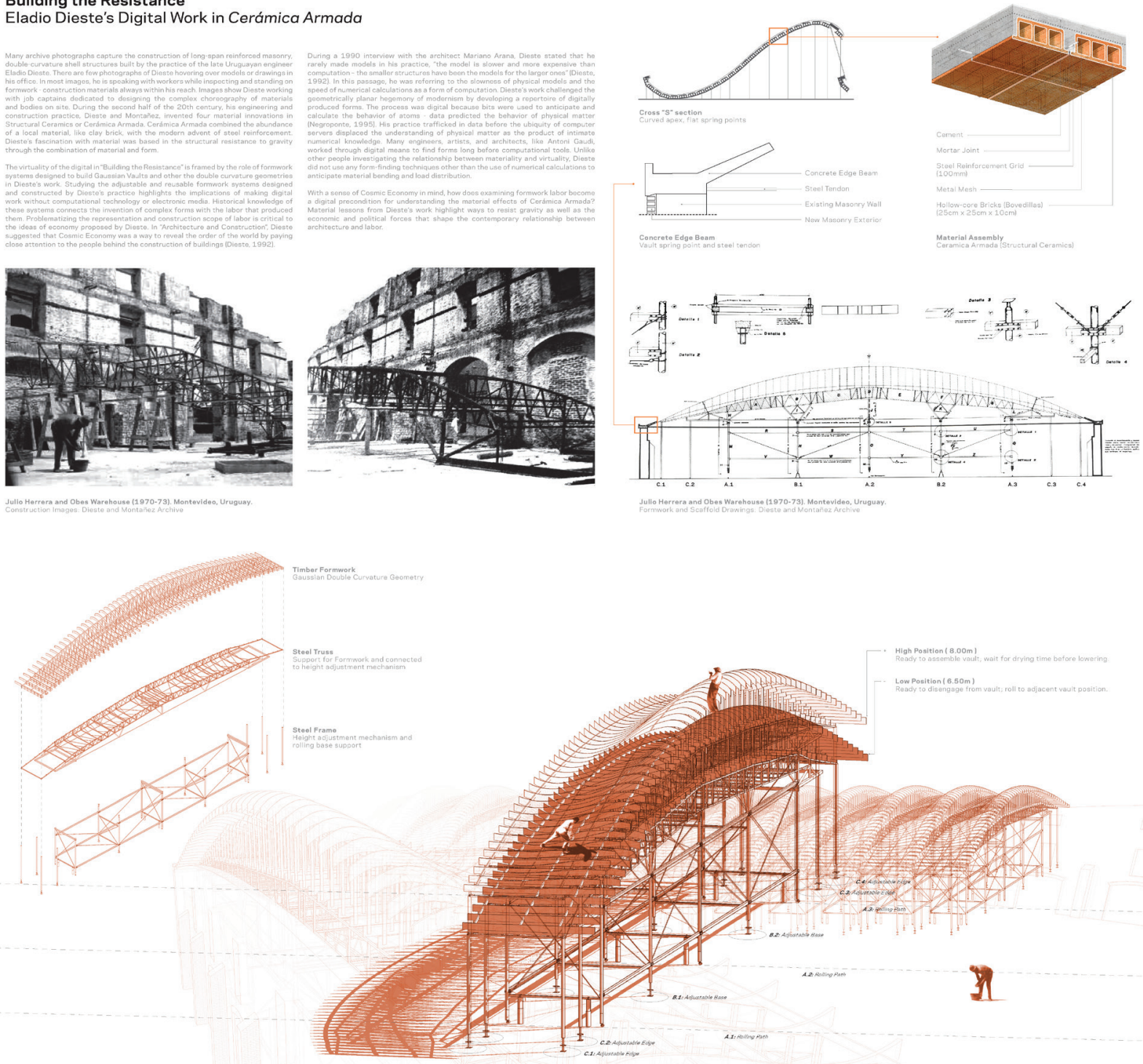